\title{
Advances in managing acute pancreatitis
}

\section{Matthew J DiMagno ${ }^{1,2 *}$, Erik-Jan Wamsteker ${ }^{1,2}$ and Anthony T DeBenedet ${ }^{1}$}

Addresses: ${ }^{1}$ Department of Internal Medicine, University of Michigan School of Medicine, 1500 East Medical Center Drive, Ann Arbor, MI 48109, USA; ${ }^{2}$ Division of Gastroenterology and Hepatology, University of Michigan School of Medicine, 1500 East Medical Center Drive, Ann Arbor, MI 48109, USA

*Corresponding author: Matthew J DiMagno (mdimagno@umich.edu)

Fl000 Medicine Reports 2009, I:59 (doi:10.34I0/MI-59)

The electronic version of this article is the complete one and can be found at: http://FI000.com/Reports/Medicine/content/I/59

\begin{abstract}
This review highlights advances in acute pancreatitis (AP) made in the past year. We focus on clinical aspects of AP - severe disease especially - and risk stratification tools to guide the clinical care of patients. Most patients with AP have mild disease that requires a diagnostic evaluation, self-limited supportive care, and a short hospital stay. In patients with potentially severe AP, it is important for clinicians to use available risk-stratifying tools to identify high-risk patients and initiate timely interventions such as aggressive fluid resuscitation, close monitoring, early initiation of enteral nutrition, and appropriate use of endoscopic retrograde cholangio-pancreatography. This approach decreases morbidity and possibly mortality and is supported by evidence drawn from recent clinical guidelines, historical literature, and the highest quality studies published in the last year.
\end{abstract}

\section{Introduction and context}

Several major clinical guidelines provide evidence-based recommendations for clinical management decisions in acute pancreatitis (AP), including those from the American College of Gastroenterology (2006) [1], the American Gastroenterology Association (2007) [2], the International Association of Pancreatology (2002) [3], and the International Critical Care Consensus Conference (2004) [4]. In this update on AP, we briefly discuss guideline recommendations and focus on epidemiology, risk factors, etiology, diagnosis, risk stratification, and recent advances in treatment, including chemoprevention of post-endoscopic retrograde cholangio-pancreatography (ERCP) pancreatitis, early ERCP treatment for acute biliary pancreatitis (ABP), intravenous fluid resuscitation, enteral nutrition (EN), antibiotic prophylaxis, and probiotic therapy.

\section{Recent advances Epidemiology}

Hospital admissions for AP are increasing in the US [5]. Brown and colleagues [5] reported a nationwide increase of $30.2 \%(P<0.001)$ after identifying $1,476,498$ admissions with a primary discharge diagnosis of AP in the National Inpatient Sample Database for the years 1997 to 2003. This increase was associated with a parallel increase in gallstone and alcohol-related pancreatitis. The authors attributed these findings to an increased incidence of $\mathrm{AP}$ and/or to more diligent diagnoses because of better diagnostic tests (for example, computed tomography [CT], endoscopic ultrasound [EUS], and ERCP). Over the time span of the study (1997 to 2003), mean mortality decreased from $1.9 \%$ to $1.4 \%$ $(P<0.001)$ and median length of stay decreased from 6.4 to 5.8 days $(P=0.002)$, which the authors ascribe to more routine use of risk stratification tools, increased availability and efficiency of diagnostic tools, and expedited triage of moderate-severe cases to aggressive management in intensive care units (ICUs) [5].

New mortality data in AP confirm that mortality rates are similar in gallstone and alcohol-induced AP [6], that mortality is $20 \%$ in those hospitalized more than 1 month with severe AP (SAP) [7], and that increased mortality occurred in those with hospital-acquired infection [8] and those at least 70 years old [9]. Finally, 
the degree of inflammation and the presence of pancreatic necrosis are associated with recurrent AP [10].

\section{Risk factors}

Cigarette smoking is an independent risk factor for AP (95\% confidence interval $=1.48$ to 3.09$)$ and total exposure correlates with overall risk [11]. Recurrent attacks of alcoholic AP, however, were not associated with cigarette smoking [12] but occurred less frequently in those who had repeated 6-month counselling sessions (to encourage sobriety) compared with a single session ( $8 \%$ versus $21 \%, P=0.042$ ) [13]. These data reinforce the common sense approach of encouraging drinking cessation.

Whether age and gender affect the risk of post-ERCP pancreatitis (PEP) is controversial $[14,15]$. According to a multicenter Chinese trial, however, PEP was associated with female gender $(P=0.002)$, age of not more than 60 years $(P=0.025)$, and other procedural factors [16]. In a smaller study, obesity was not a risk factor for PEP [17], however, an increased risk of PEP was associated with current alcohol use and former smoking $(P<0.0001$, $P=0.013)[18]$.

\section{Chemoprevention of post-ERCP pancreatitis}

Several groups (re)examined chemoprevention therapy for PEP by randomized controlled trials (RCTs) [19-23] and meta-analyses [24-29] and reported inconclusive results for allopurinol $[19,24,25]$, corticosteroids [26], unfractionated heparin [20], and intravenous nitroglycerin $[21,27,28]$. One exception is that prophylactic rectal nonsteroidal anti-inflammatory drugs (indomethacin or diclofenac) may reduce PEP, based on data from RCTs $[22,30]$ and a meta-analysis of four RCTs [29]. For unclear reasons, the route of drug delivery may have critical importance; oral diclofenac did not reduce PEP [23]. A large, multicenter, prospective RCT is warranted to determine whether rectally delivered diclofenac reduces PEP in high-risk patients.

\section{Etiology and diagnosis}

ERCP is an effective diagnostic and therapeutic test to evaluate patients with suspected biliary obstructive diseases. Unfortunately, ERCP has risks of pancreatitis, cholangitis, perforation, and hemorrhage. To compare clinical approaches, Lee and colleagues [31] randomly assigned 65 patients with suspected biliary obstruction to an initial ERCP versus EUS. Biliary lesions were detected in seven out of $33(22 \%)$ ERCP patients and nine out of $32(27 \%)$ EUS patients and were treated endoscopically. Serious complications were not significantly higher in the ERCP versus EUS group. Because $75 \%$ of patients had no biliary lesion, the authors concluded that most patients can avoid an unnecessary ERCP if EUS is used as a tool to select appropriate patients for ERCP.

Investigators previously established that patients with severe chronic renal insufficiency have pancreatic lesions [32] and a predilection to pancreatic diseases [33]. Also, Owyang and colleagues [34,35] reported that patients with renal failure undergoing hemodialysis (HD) have increased circulatory gastrointestinal hormones, particularly cholecystokinin (CCK) [34] and increased secretion of trypsin [35], which the authors postulated could initiate pancreatic disease in this group of patients [35]. To investigate the incidence and severity of AP associated with chronic dialysis, Lankisch and colleagues [36] surveyed dialysis center physicians in Germany. Seventy-two percent of physicians responded. After excluding patients with a known cause of AP, the authors found that dialysis, particularly peritoneal dialysis (PD), was a risk factor for developing AP. The rates of incidence of AP (per 100,000) in patient groups were 168 for PD, 32 for HD, and 19.7 for the general population. Finally, the severity of AP was generally greater in $\mathrm{PD}$ than $\mathrm{HD}$ patients. We caution that renal disease rather than treatment (dialysis) may increase the risk of AP because renal disease without dialysis was not included as a control population and because other investigators reported a higher risk of $\mathrm{AP}$ in patients undergoing $\mathrm{PD}$ versus HD (18.4 versus 16.5 per 1,000 person-years; $P=0.033$ [ [37]. Differences between these studies may be attributable to biases from the retrospective design, incomplete data collection, over- or under-reporting of $\mathrm{AP}$, or other biases.

\section{Risk stratification}

Investigators recently [38] reconfirmed an older observation [39] and conclusions from a practice guideline [1] that persistent early organ failure ( $>48$ hours) and pancreatic necrosis (which may not be detectable for 72 hours) are the two most important indicators of severity in AP [1]. Within the first 48 hours of presentation, however, these parameters rarely aid risk stratification, which is important for prognosis, triage, and directed treatment aimed at decreasing morbidity and possibly mortality. Other methods of risk stratification in AP suffer from the same limitation (Ranson and Glasgow scores require 48 hours to complete) or require many factors, including those not directly relevant to AP prognosis [Acute Physiology and Chronic Health Evaluation II (APACHE II)]. Recent investigators studied whether computer-based and/or simple scoring systems quickly and accurately predicted severity and mortality of $\mathrm{AP}$ at presentation. 
Computer-based algorithms may improve the prediction of severity by using machine learning, including artificial neural networks [40,41]. Pearce and colleagues [42] reported in a retrospective study that kernel logistic regression and bootstrapping employing eight variables had $87 \%$ sensitivity and $71 \%$ specificity for predicting SAP, values superior to APACHE II. Wu and colleagues [43] developed a simple, five-component, prognostic clinical score by performing a classification and regression tree (CART) analysis on data collected from 17,992 cases of AP hospitalized during the period of 2000 to 2001. The authors identified five variables during the first 24 hours which predict in-hospital mortality based on a BISAP (contraction for the five variables) score of 0 to 5: blood urea nitrogen (BUN) of greater than $25 \mathrm{mg} /$ days, impaired mental status, systemic inflammatory response syndrome (SIRS), age of more than 60 years, or the presence of a pleural effusion. Mortality ranged from less than $1 \%$ ( 0 to 1 point) to as high as $26.7 \%$ (5 points). As a third risk stratification tool, the early warning score (EWS), a simple physiological scoring system that monitors patient progress, predicts mortality of AP based on five bedside parameters: blood pressure, urine output, respiratory rate, pulse rate, and level of consciousness. In a retrospective analysis of 181 patients hospitalized with AP, EWS was as accurate as APACHE II but easier to use for predicting mortality up to 3 days after initial presentation [44].

The 1992 Atlanta classification of AP remains the only classification system used widely by clinicians because it was an attempt to achieve uniform criteria to determine clinical severity and complications of AP. Unfortunately, as Bollen and colleagues [45] reported after reviewing 447 articles, many of the original definitions have shortcomings and standardized definitions frequently are not used to predict SAP. Clinical trials, therefore, are heterogeneous; thus, it is difficult if not impossible to compare studies or pool data to generate evidence-based recommendations. Subsequently, the authors suggested that an update or a new classification of AP was needed.

\section{Fluid resuscitation}

Recently published guidelines strongly urge adequate early fluid resuscitation to correct intravascular volume depletion (Table 1) [1,2,46-49], a leading contributor to necrotizing pancreatitis. Gardner and colleagues [9], however, pointed out that often there are only experimental animal data or uncontrolled human data but no prospective human studies to use as a basis for making recommendations. Unanswered questions include the best measure of intravascular volume status, the optimal fluid type (crystalloid versus colloid), optimal volume of fluid resuscitation, optimal timing of fluid administration in the course of AP, and the frequency and type of complications due to fluid resuscitation.

In the absence of reliable data, the authors [9] recommended that the adequacy of fluid resuscitation be determined by frequent vitals, urinary output, and measures of hemoconcentration [9]. A pitfall of aggressive volume resuscitation is the risk of inducing pulmonary edema/fluid overload. Underlying morbid conditions or clinical indicators of predicted SAP may precipitate admission to an ICU for hemodynamic assessment. To assess preload, intrathoracic blood volume index (ITBI) might be superior to measurement of central venous pressure (CVP). It is important to point out that the use of ITBI requires ICU care because invasive monitoring with arterial line and pulmonary artery catheter to perform transpulmonary thermodilution is required. According to a recent study [50], ITBI and changes in ITBI correlated significantly with cardiac index (CI) and changes in CI, respectively, but CVP did not. An additional advantage of ITBI is that mechanical ventilation impairs measurement of CVP and pulmonary capillary wedge pressure (PCWP), but not ITBI. Furthermore, when ITBI was used as the gold standard, CVP and hematocrit had unacceptably low sensitivities for

Table I. Fluid resuscitation recommendations from recent reviews of acute pancreatitis

\begin{tabular}{lll}
\hline Investigators & Journal, year & Initial resuscitation recommendation $^{2}$ \\
\hline Pandol, et al. [46] & Gastroenterology, 2007 & $\begin{array}{l}\text { Severe volume depletion: } 500-1,000 \mathrm{cc} / \mathrm{hour} \\
\text { Nonpancreatic fluid loss: } 300-500 \mathrm{cc} / \mathrm{hour} \\
\text { No volume depletion: } 250-350 \mathrm{cc} / \mathrm{hour} \\
\text { Vigorous fluid resuscitation }\end{array}$ \\
Forsmark and Baillie [2] & Gastroenterology, 2007 & $\begin{array}{l}\text { Urine output } \geq 0.5 \mathrm{~mL} / \mathrm{kg} \text { body weight/hour } \\
\text { Fluid bolus to achieve hemodynamic stability } \\
\text { followed by } 250-500 \mathrm{~mL} / \mathrm{hour} \text { of crystalloid }\end{array}$ \\
Whitcomb [47] & N Engl J Med, 2006 & Aggressive intravenous fluid replacement \\
Banks and Freeman [1] & Aggressive fluid resuscitation \\
Swaroop, et al. [48] & Am J Gastroenterol, 2006 & At least 250-300 cc/hour for 48 hours \\
\hline
\end{tabular}

${ }^{a}$ Assuming normal-sized individual without cardiac, pulmonary, or renal compromise. Adapted with permission from Elsevier [9]. 
volume depletion ( $0 \%$ and $22 \%$, respectively); therefore, ITBI is more appropriate than CVP or hematocrit for volume management.

\section{ERCP treatment for pancreatitis}

There is consensus [1-4] that (a) ERCP and endoscopic sphincterotomy are indicated within 24 hours in patients with $\mathrm{ABP}$ with obstructive jaundice and/or acute cholangitis and (b) routine ERCP prior to cholecystectomy is not required in most patients with $\mathrm{ABP}$ and mild disease because bile duct stones typically pass spontaneously. Consensus is lacking, however, as to whether ERCP and endoscopic sphincterotomy should be performed within 72 hours to manage patients with severe ABP without jaundice or cholangitis. Guidelines cautiously endorse early ERCP in this population, particularly in those with evidence of organ failure. Yet two recent meta-analyses provide little enthusiasm for this approach. In two separate meta-analyses [51,52], investigators reported that early ERCP had no significant impact on mortality [51,52], including a subgroup of patients with predicted SAP $[51,52]$ and that early ERCP had no effect on complications [51] or reduced complications in patients with predicted SAP [52]. The modestly different conclusions reached by these two meta-analyses may be due to many factors, including different inclusion data and methodological quality and the use of different definitions for 'early' ERCP, predicted severity of $\mathrm{ABP}$, complications, and cholangitis.

\section{Nutrition}

Recent clinical guidelines $[1,4,53]$ and a technical review [2] recommend administering EN rather than parenteral nutrition (PN) or no nutrition to (a) patients with predicted SAP or (b) those who will not be able to consume food for several weeks. EN is a less costly nutritional choice than $\mathrm{PN}$ and appears to reduce infectious complications, possibly by maintaining gut integrity (as a source of bacterial infection) and/or augmenting glycemic control [54]. This endpoint is clinically important because infectious complications are responsible for up to $50 \%$ of mortality in patients with SAP $[39,48,55]$; when mortality from infection occurs, it usually does so more than 14 days into the disease course. Two recent meta-analyses $[56,57]$ show that EN versus $\mathrm{PN}$ reduces the risk of infectious complications and mortality in patients with predicted SAP. Only the larger meta-analysis (six versus five RCTs) [57] showed that EN versus PN reduced organ failure, likely because of greater power. Similar to these observations, three recent systematic reviews reported that EN versus PN reduces the risk of infectious complications in patients with predicted SAP [58-60]. Interestingly, one systematic review [61] also reported that only early EN (started at less than 24 or 48 hours) reduced multiple organ failure and pancreatic infectious complications and that delayed EN ( $>48$ hours) or PN had no effect on these endpoints. Despite the promise of using EN to reduce morbidity, organ failure, and mortality in predicted SAP, it is important to identify specific limitations of RCTs included in these meta-analyses: small size, inconsistent masking of investigators/patients, and variable definitions for organ failure and criteria for predicting disease severity. Across studies, there were also differences in the type of enteral tube (nasogastric versus nasojejunal), the starting time of EN after admission (range from less than 6 to more than 96 hours), the feeding formula, and the use of prophylactic antibiotics (73-100\%). Further study is required to determine the appropriate timing of starting EN, the optimal rate and composition $[62,63]$ of EN, and whether nasogastric EN has safety and effectiveness similar to those of nasojejunal EN [64]. Currently, the National Institutes of Health is funding a multicenter trial to compare the outcomes of nasogastric versus mid-jejunal feeding in patients with SAP.

\section{Antibiotics}

Recent clinical guidelines [1,4], a technical review [2], and expert opinion $[65,66]$ do not recommend prophylactic systemic antibiotics in patients with acute necrotizing pancreatitis (ANP). This recommendation arises from the data of two large ( $\mathrm{n}=100$ to 114 patients), multicenter ( $\mathrm{n}=19$ to 32 centers), double-blind RCTs $[67,68]$; prophylactic antibiotic treatment with Meropenem [67] or ciprofloxacin plus flagyl [68] had no beneficial effect on patients with confirmed ANP [67] or predicted SAP [68]. Similarly, investigators of a recent but smaller $(\mathrm{n}=46)$ double-blind RCT reported that prophylactic administration of intravenous ciprofloxacin did not reduce pancreatic infections or mortality in patients with confirmed ANP ( $\mathrm{n}=46$ patients) [69]. Perhaps starting antibiotic prophylaxis earlier than 72 to 120 hours after the onset of symptoms $[67,68]$ rather than waiting for pancreatic necrosis to appear on CT imaging (usually occurs 72 hours after the onset of symptoms) might allow better penetration of antibiotics into pancreatic tissue and reduce infection $[70,71]$. Answering this question requires starting antibiotics within 24 hours of symptom onset on the basis of the presence of SIRS or predicted SAP [67,69].

The results of five meta-analyses [72-76] performed since 2006 add little new information but are varied and contrast with findings of the two large, multicenter RCTs. Three meta-analyses show that prophylactic antibiotics for ANP and/or SAP reduce hospital stay [74-76], one shows a reduction in infected necrosis and nonpancreatic infections [75], and none shows an effect on the rate of 
surgical interventions or mortality. Although subgroup analyses performed in one meta-analysis raised the possibly that the use of carbapenems is critical to outcomes [75], the largest and highest quality RCT using Meropenem was negative [67], and the metaanalysis with a stricter requirement for methodological quality was negative [72].

Hence, based on evidence from well-designed, doubleblind RCTs, we do not recommend the use of prophylactic antibiotics for ANP. According to expert opinion $[65,66,68]$, prophylactic antibiotics may be considered to treat patients who have evidence of SIRS or failure of one or more organs, but this remains controversial and requires further study. Finally, we recommend antibiotics when patients have evidence of sepsis or proven pancreatic or extrapancreatic infection.

\section{Probiotics}

Besselink and colleagues [77] hypothesized that, similar to the use of EN, probiotic treatment might reduce infectious complications in SAP by 'reducing smallbowel bacterial overgrowth, restoring gastrointestinal barrier function, and modulating the immune system'. Two small ( $\mathrm{n}=45$ to 60 patients), double-blind RCTs performed by the same group of investigators reported conflicting effects of probiotics on infected necrosis in patients with AP $[78,79]$. The much larger $(n=298$ patients) double-blind RCT by Besselink and colleagues [77] included only those with predicted SAP and administered a multispecies probiotic preparation or placebo (with the EN) starting within 72 hours of the onset of symptoms and continuing twice daily for 28 days. Surprisingly, probiotic prophylaxis did not reduce the risk of infectious complications and was associated with a higher incidence of bowel ischemia (9/153 versus $0 / 145, P=0.004)$ and greater mortality (relative risk $=2.53,95 \%$ confidence interval $=1.22$ to $5.25)$, leading to the logical recommendation that probiotic prophylaxis not be administered in this category of patients until the mechanisms of these adverse events have been clarified [77].

\section{Implications for clinical practice}

The primary determinants of mortality in patients with AP are organ failure during the early phase (from onset to 14 days) and infected necrosis in the late phase ( $>2$ weeks of illness). To reduce morbidity and possibly mortality, we recommend an expedient workup and risk stratification of these patients at the point of contact, usually the emergency department. Fortunately, new user-friendly risk stratification tools (for example, BISAP) may simplify and expedite the triage of these patients to an appropriate level of care, which differs markedly for high- and low-risk groups. Immediate treatment decisions for the high-risk group (patients with organ failure or predicted SAP) include aggressive resuscitation (for example, $250-500 \mathrm{mg} /$ hour), hemodynamic monitoring (for example, ITBI), hourly clinical reassessment in an ICU or stepdown unit, and involvement of a multidisciplinary team. Urgent decisions include ERCP for some cases of biliary pancreatitis, initiation of EN after fluid resuscitation (24-48 hours) and reservation of antibiotics for evidence of sepsis or SIRS, failure of one or more organs, proven pancreatic or extrapancreatic infection, or an increase in C-reactive protein with evidence of pancreatic or extrapancreatic infection. Late decision making involves continued reassessment, monitoring for complications, aspiration and possibly drainage when infected necrosis is suspected, and timely cholecystectomy when warranted. Table 2 summarizes major advances in acute pancreatitis (AP) made in the past year that may affect clinical practice.

\section{Abbreviations \\ $\mathrm{ABP}$, acute biliary pancreatitis; $\mathrm{ANP}$, acute necrotizing pancreatitis; AP, acute pancreatitis; APACHE II, Acute Physiology and Chronic Health Evaluation II; BISAP, blood urea nitrogen, impaired mental status, systemic}

\section{Table 2. Review highlights}

- Hospital admissions for acute pancreatitis (AP) are increasing in the US, yet mortality and length of stay are decreasing.

- Cigarette smoking is an independent risk factor for AP, and total exposure correlates with overall risk.

- Renal disease is associated with AP, but it remains unclear whether the mode of dialysis increases this risk further.

- The user-friendly BISAP (blood urea nitrogen, impaired mental status, systemic inflammatory response syndrome, age, and pleural effusion) score can be calculated rapidly from five variables during the first 24 hours and predicts in-hospital mortality.

- Intrathoracic blood volume index is superior to central venous pressure and hematocrit for assessing volume depletion and guiding fluid resuscitation in AP.

- Consensus is lacking on whether endoscopic retrograde cholangio-pancreatography and endoscopic sphincterotomy should be performed within 72 hours to manage patients with severe biliary AP without jaundice or cholangitis.

- Enteral nutrition reduces the risk of infectious complications and mortality in patients with severe AP.

- Prophylactic systemic antibiotics are not recommended for patients with necrotizing AP.

- It remains controversial whether prophylactic antibiotics are indicated for systemic inflammatory response syndrome or failure of one or more organs in patients with AP.

- Probiotics are associated with a higher incidence of bowel ischemia and greater mortality in patients with severe AP and should not be used. 
inflammatory response syndrome, age, and pleural effusion; BUN, blood urea nitrogen; CART, classification and regression tree; CCK, cholecystokinin; $\mathrm{CI}$, cardiac index; CT, computed tomography; CVP, central venous pressure; EN, enteral nutrition; ERCP, endoscopic retrograde cholangio-pancreatography; EUS, endoscopic ultrasound; EWS, early warning score; HD, hemodialysis; ICU, intensive care unit; ITBI, intrathoracic blood volume index; PCWP, pulmonary capillary wedge pressure; PD, peritoneal dialysis; PEP, post-ERCP (endoscopic retrograde cholangio-pancreatography) pancreatitis; PN, parenteral nutrition; RCT, randomized controlled trial; SAP, severe acute pancreatitis; SIRS, systemic inflammatory response syndrome.

\section{Competing interests}

MJD received honoraria from Lippincott Williams \& Wilkins (Philadelphia, PA, USA) (for articles published in Current Opinion in Gastroenterology from 2003 to 2007), honoraria from the British Medical Journal (for an article published in BMJ Point of Care in 2007), and a consulting fee from MD Evidence (Atlantic City, NJ, USA) (for co-authoring a systematic review [80]). E-JW and ATD declare that they have no competing interests. This research was supported by an educational grant from Altus Pharmaceuticals (Waltham, MA, USA).

\section{Acknowledgments}

MJD receives research support from National Institute of Health grants K08 DK073298 and R21 AA017271.

\section{References}

I. Banks PA, Freeman ML: Practice guidelines in acute pancreatitis. Am J Gastroenterol 2006, 10 1:2379-400.

2. Forsmark CE, Baillie J; AGA Institute Clinical Practice and Economics Committee; AGA Institute Governing Board: AGA Institute technical review on acute pancreatitis. Gastroenterology 2007, 132:2022-44.

3. Uhl W, Warshaw A, Imrie C, Bassi C, McKay CJ, Lankisch PG, Carter R, Di Magno E, Banks PA, Whitcomb DC, Dervenis C, Ulrich CD, Satake K, Ghaneh P, Hartwig W, Werner J, McEntee G, Neoptolemos JP, Büchler MW; International Association of Pancreatology: IAP Guidelines for the Surgical Management of Acute Pancreatitis. Pancreatology 2002, 2:565-73.

4. Nathens AB, Curtis JR, Beale RJ, Cook DJ, Moreno RP, Romand JA, Skerrett SJ, Stapleton RD, Ware LB, Waldmann CS: Management of the critically ill patient with severe acute pancreatitis. Crit Care Med 2004, 32:2524-36.

5. Brown A, Young B, Morton J, Behrns K, Shaheen N: Are health related outcomes in acute pancreatitis improving? An analysis of national trends in the U.S. from 1997 to 2003. JOP 2008, 9:408-I4.

6. Andersen AM, Novovic S, Ersboll AK, Hansen MB: Mortality in alcohol and biliary acute pancreatitis. Pancreas 2008, 36:432-4.

7. Gigout J, Desjeux A, Vitton V, Gasmi M, Subtil C, Grimaud JC, Barthet $M$ : What is the outcome for patients presenting with severe acute pancreatitis requiring a hospital stay of more than one month? Gastroenterol Clin Biol 2009, 33:2 10-6.
8. Wu BU, Johannes RS, Kurtz S, Banks PA: The impact of hospitalacquired infection on outcome in acute pancreatitis. Gastroenterology 2008, 135:816-20.

FI000 Factor 9.0 Exceptional

Evaluated by Matthew DiMagno 30 Oct 2008

9. Gardner TB, Vege SS, Pearson RK, Chari ST: Fluid resuscitation in acute pancreatitis. Clin Gastroenterol Hepatol 2008, 6:1070-6.

10. Yasuda T, Ueda T, Takeyama Y, Shinzeki M, Sawa H, Nakajima T, Kuroda $Y$ : Long-term outcome of severe acute pancreatitis. J Hepatobiliary Pancreat Surg 2008, 15:397-402.

II. Lindkvist B, Appelros S, Manjer J, Berglund G, Borgstrom A: A prospective cohort study of smoking in acute pancreatitis. Pancreatology 2008, 8:63-70.

12. Pelli H, Lappalainen-Lehto R, Piironen A, Sand J, Nordback I: Risk factors for recurrent acute alcohol-associated pancreatitis: a prospective analysis. Scand J Gastroenterol 2008, 43:614-2I.

13. Nordback I, Pelli H, Lappalainen-Lehto R, Jarvinen S, Raty S, Sand J: The recurrence of acute alcohol-associated pancreatitis can be reduced: a randomized controlled trial. Gastroenterology 2008, I36:848-55.

FI000 Factor 6.0 Must Read

Evaluated by Dhiraj Yadav 27 Feb 2009

14. Cheng CL, Sherman S, Watkins JL, Barnett J, Freeman M, Geenen J, Ryan M, Parker H, Frakes JT, Fogel EL, Silverman WB, Dua KS, Aliperti G, Yakshe P, Uzer M, Jones W, Goff J, Lazzell-Pannell L, Rashdan A, Temkit M, Lehman GA: Risk factors for post-ERCP pancreatitis: a prospective multicenter study. Am J Gastroenterol 2006, I0I:139-47.

15. Freeman ML, DiSario JA, Nelson DB, Fennerty MB, Lee JG, Bjorkman DJ, Overby CS, Aas J, Ryan ME, Bochna GS, Shaw MJ, Snady HW, Erickson RV, Moore JP, Roel JP: Risk factors for postERCP pancreatitis: a prospective, multicenter study. Gastrointest Endosc 200I, 54:425-34.

16. Wang $P$, Li ZS, Liu F, Ren $X$, Lu NH, Fan ZN, Huang $Q$, Zhang $X$, He LP, Sun WS, Zhao Q, Shi RH, Tian ZB, Li YQ, Li W, Zhi FC: Risk factors for ERCP-related complications: a prospective multicenter study. Am J Gastroenterol 2009, 104:3 I-40.

17. Deenadayalu VP, Blaut U, Watkins JL, Barnett J, Freeman M, Geenen J, Ryan M, Parker H, Frakes JT, Fogel EL, Silverman WB, Dua KS, Aliperti G, Yakshe P, Uzer M, Jones W, Goff J, Temkit M, Lehman GA, Sherman S: Does obesity confer an increased risk and/or more severe course of post-ERCP pancreatitis? a retrospective, multicenter study. J Clin Gastroenterol 2008, 42: I I 03-9.

18. DeBenedet AT, Raghunathan TE, Wing JJ, Wamsteker EJ, DiMagno MJ: Current alcohol use and former cigarette smoking as risk factors for post-endoscopic retrograde cholangiopancreatography pancreatitis. Clin Gastroenterol Hepatol 2009, 7:353-8.

19. Romagnuolo J, Hilsden R, Sandha GS, Cole M, Bass S, May G, Love J, Bain VG, McKaigney J, Fedorak RN: Allopurinol to prevent pancreatitis after endoscopic retrograde cholangiopancreatography: a randomized placebo-controlled trial. Clin Gastroenterol Hepatol 2008, 6:465-7I.

FI000 Factor 6.0 Must Read Evaluated by Matthew DiMagno 2 Jun 2008

20. Barkay O, Niv E, Santo E, Bruck R, Hallak A, Konikoff FM: Low-dose heparin for the prevention of post-ERCP pancreatitis: a randomized placebo-controlled trial. Surg Endosc 2008, 22: $197 \mid-6$.

21. Beauchant $M$, Ingrand $P$, Favriel JM, Dupuychaffray JP, Capony $P$, Moindrot H, Barthet M, Escourrou J, Plane C, Barrioz T, Lacoste L, Ingrand I: Intravenous nitroglycerin for prevention of pancreatitis after therapeutic endoscopic retrograde cholangiography: a randomized, double-blind, placebo-controlled multicenter trial. Endoscopy 2008, 40:63।-6.

22. Khoshbaten M, Khorram H, Madad L, Ehsani Ardakani MJ, Farzin H, Zali MR: Role of diclofenac in reducing post-endoscopic 
retrograde cholangiopancreatography pancreatitis. J Gastroenterol Hepatol 2008, 23:el I-6.

23. Cheon YK, Cho KB, Watkins JL, McHenry L, Fogel EL, Sherman S, Schmidt S, Lazzell-Pannell L, Lehman GA: Efficacy of diclofenac in the prevention of post-ERCP pancreatitis in predominantly high-risk patients: a randomized double-blind prospective trial. Gastrointest Endosc 2007, 66: I I26-32.

24. Bai Y, Gao J, Zhang W, Zou D, Li Z: Meta-analysis: allopurinol in the prevention of postendoscopic retrograde cholangiopancreatography pancreatitis. Aliment Pharmacol Ther 2008, 28:557-64.

25. Zheng M, Chen Y, Bai J, Xin Y, Pan X, Zhao L: Meta-analysis of prophylactic allopurinol use in post-endoscopic retrograde cholangiopancreatography pancreatitis. Pancreas 2008, 37:247-53.

26. Zheng M, Bai J, Yuan B, Lin F, You J, Lu M, Gong Y, Chen Y: Metaanalysis of prophylactic corticosteroid use in post-ERCP pancreatitis. BMC Gastroenterol 2008, 8:6.

27. Shao LM, Chen QY, Chen MY, Cai JT: Nitroglycerin in the prevention of Post-ERCP pancreatitis: a meta-analysis. Dig Dis Sci 2009, [Epub ahead of print].

28. Bang UC, Nøjgaard C, Andersen PK, Matzen P: Meta-analysis: nitroglycerin for prevention of post-ERCP pancreatitis. Aliment Pharmacol Ther 2009, 29:1078-85.

29. Elmunzer BJ, Waljee AK, Elta GH, Taylor JR, Fehmi SM, Higgins PD: A meta-analysis of rectal NSAIDs in the prevention of postERCP pancreatitis. Gut 2008, 57:| 262-7.

30. Lankisch PG: Indomethacin may reduce the incidence and severity of acute pancreatitis after ERCP. Am J Gastroenterol 2008, I 03:244.

31. Lee YT, Chan FK, Leung WK, Chan HL, Wu JC, Yung MY, Ng EK, Lau JY, Sung J: Comparison of EUS and ERCP in the investigation with suspected biliary obstruction caused by choledocholithiasis: a randomized study. Gastrointest Endosc 2008, 67:660-8.

32. Baggenstoss $\mathrm{AH}$ : The pancreas in uremia: a histopathologic study. Am J Pathol 1948, 24:1003-17.

33. Avram MM: High prevalence of pancreatic disease in chronic renal failure. Nephron 1977, 18:68-7I.

34. Owyang C, Miller LJ, DiMagno EP, Brennan LA Jr, Go VL: Gastrointestinal hormone profile in renal insufficiency. Mayo Clin Proc 1979, 54:769-73.

35. Owyang C, Miller LJ, DiMagno EP, Mitchell JC 3rd, Go VL: Pancreatic exocrine function in severe human chronic renal failure. Gut 1982, 23:357-6I.

36. Lankisch PG, Weber-Dany B, Maisonneuve $P$, Lowenfels $A B$ : Frequency and severity of acute pancreatitis in chronic dialysis patients. Nephrol Dial Transplant 2008, 23: I40I-5.

37. Quraishi ER, Goel S, Gupta M, Catanzaro A, Zasuwa G, Divine G: Acute pancreatitis in patients on chronic peritoneal dialysis: an increased risk? Am J Gastroenterol 2005, I00:2288-93.

38. Lytras D, Manes K, Triantopoulou C, Paraskeva C, Delis S, Avgerinos C, Dervenis C: Persistent early organ failure: defining the high-risk group of patients with severe acute pancreatitis? Pancreas 2008, 36:249-54.

39. Johnson $C D$, Abu-Hilal M: Persistent organ failure during the first week as a marker of fatal outcome in acute pancreatitis. Gut 2004, 53:1340-4.

40. Pofahl WE, Walczak SM, Rhone E, Izenberg SD: Use of an artificial neural network to predict length of stay in acute pancreatitis. Am Surg 1998, 64:868-72.

4I. Keogan MT, Lo JY, Freed KS, Raptopoulos V, Blake S, Kamel IR, Weisinger K, Rosen MP, Nelson RC: Outcome analysis of patients with acute pancreatitis by using an artificial neural network. Acad Radiol 2002, 9:410-9.

42. Pearce CB, Gunn SR, Ahmed A, Johnson CD: Machine learning can improve prediction of severity in acute pancreatitis using admission values of APACHE II score and C-reactive protein. Pancreatology 2006, 6:|23-3|.

43. Wu BU, Johannes RS, Sun X, Tabak Y, Conwell DL, Banks PA: The early prediction of mortality in acute pancreatitis: a large population-based study. Gut 2008, 57:1698-703.

FI000 Factor 6.0 Must Read

Evaluated by Chris Forsmark I Jul 2008

44. Garcea G, Gouda M, Hebbes C, Ong SL, Neal CP, Dennison AR, Berry DP: Predictors of severity and survival in acute pancreatitis: validation of the efficacy of early warning scores. Pancreas 2008, 37:e54-6I.

45. Bollen TL, van Santvoort HC, Besselink MG, van Leeuwen MS, Horvath KD, Freeny PC, Gooszen HG: The Atlanta Classification of acute pancreatitis revisited. $\mathrm{Br} J$ Surg 2008, 95:6-2I.

46. Pandol SJ, Saluja AK, Imrie CW, Banks PA: Acute pancreatitis: bench to the bedside. Gastroenterology 2007, I32: I |27-5 I.

47. Whitcomb DC: Clinical practice. Acute pancreatitis. N Engl J Med 2006, 354:2142-50.

48. Swaroop VS, Chari ST, Clain JE: Severe acute pancreatitis. JAMA 2004, 29I:2865-8.

49. Tenner S: Initial management of acute pancreatitis: critical issues during the first 72 hours. Am J Gastroenterol 2004, 99:2489-94.

50. Huber $W$, Umgelter $A$, Reind $W$, Franzen $M$, Schmidt $C$, von Delius S, Geisler F, Eckel F, Fritsch R, Siveke J, Henschel B, Schmid RM: Volume assessment in patients with necrotizing pancreatitis: a comparison of intrathoracic blood volume index, central venous pressure, and hematocrit, and their correlation to cardiac index and extravascular lung water index. Crit Care Med 2008, 36:2348-54.

5I. Petrov MS, van Santvoort HC, Besselink MG, van der Heijden GJ, van Erpecum KJ, Gooszen HG: Early endoscopic retrograde cholangiopancreatography versus conservative management in acute biliary pancreatitis without cholangitis: a meta-analysis of randomized trials. Ann Surg 2008, 247:250-7.

52. Moretti A, Papi C, Aratari A, Festa V, Tanga M, Koch M, Capurso L: Is early endoscopic retrograde cholangiopancreatography useful in the management of acute biliary pancreatitis? A metaanalysis of randomized controlled trials. Dig Liver Dis 2008, 40:379-85.

53. Meier R, Ockenga J, Pertkiewicz M, Pap A, Milinic N, Macfie J, Loser C, Keim V: ESPEN Guidelines on Enteral Nutrition: Pancreas. Clin Nutr 2006, 25:275-84.

54. Petrov MS, Zagainov VE: Influence of enteral versus parenteral nutrition on blood glucose control in acute pancreatitis: a systematic review. Clin Nutr 2007, 26:5 I4-23.

55. Gloor B, Muller CA, Worni M, Martignoni ME, Uhl W, Buchler MW: Late mortality in patients with severe acute pancreatitis. $\mathrm{Br} J$ Surg 200I, 88:975-9.

56. Petrov MS, van Santvoort HC, Besselink MG, van der Heijden G], Windsor JA, Gooszen HG: Enteral nutrition and the risk of mortality and infectious complications in patients with severe acute pancreatitis: a meta-analysis of randomized trials. Arch Surg 2008, I 43: I I I I-7.

FI000 Factor 3.0 Recommended Evaluated by Jan De Waele 4 Dec 2008

57. Cao Y, Xu Y, Lu T, Gao F, Mo Z: Meta-analysis of enteral nutrition versus total parenteral nutrition in patients with severe acute pancreatitis. Ann Nutr Metab 2008, 53:268-75.

58. Marik PE, Zaloga GP: Meta-analysis of parenteral nutrition versus enteral nutrition in patients with acute pancreatitis. BMJ 2004, 328: 1407.

59. McClave SA, Chang WK, Dhaliwal R, Heyland DK: Nutrition support in acute pancreatitis: a systematic review of the literature. JPEN J Parenter Enteral Nutr 2006, 30: I43-56.

60. Petrov MS, Pylypchuk RD, Emelyanov NV: Systematic review: nutritional support in acute pancreatitis. Aliment Pharmacol Ther 2008, 28:704-12. 
6I. Petrov MS, Pylypchuk RD, Uchugina AF: A systematic review on the timing of artificial nutrition in acute pancreatitis. $\mathrm{Br} J \mathrm{Nutr}$ 2009, 101:787-93.

62. Petrov MS, Atduev VA, Zagainov VE: Advanced enteral therapy in acute pancreatitis: is there a room for immunonutrition? A meta-analysis. Int J Surg 2008, 6:1 19-24.

63. Wang $X$, Li W, Li N, Li J: Omega-3 fatty acids-supplemented parenteral nutrition decreases hyperinflammatory response and attenuates systemic disease sequelae in severe acute pancreatitis: a randomized and controlled study. JPEN J Parenter Enteral Nutr 2008, 32:236-4I.

64. Petrov MS, Correia MI, Windsor JA: Nasogastric tube feeding in predicted severe acute pancreatitis. A systematic review of the literature to determine safety and tolerance. JOP 2008, 9:440-8.

65. Lankisch PG, Lerch MM: Pharmacological prevention and treatment of acute pancreatitis: where are we now? Dig Dis 2006, 24:148-59.

66. DiMagno MJ, DiMagno EP: New advances in acute pancreatitis. Curr Opin Gastroenterol 2007, 23:494-50I.

67. Dellinger EP, Tellado JM, Soto NE, Ashley SW, Barie PS, Dugernier T, Imrie CW, Johnson CD, Knaebel HP, Laterre PF, Maravi-Poma E, Kissler JJ, Sanchez-Garcia M, Utzolino S: Early antibiotic treatment for severe acute necrotizing pancreatitis: a randomized, double-blind, placebo-controlled study. Ann Surg 2007, 245:674-83.

68. Isenmann R, Runzi M, Kron M, Kahl S, Kraus D, Jung N, Maier L, Malfertheiner P, Goebell H, Beger HG: Prophylactic antibiotic treatment in patients with predicted severe acute pancreatitis: a placebo-controlled, double-blind trial. Gastroenterology 2004, 1 26:997-1004.

69. Garcia-Barrasa A, Borobia FG, Pallares R, Jorba R, Poves I, Busquets ], Fabregat J: A double-blind, placebo-controlled trial of ciprofloxacin prophylaxis in patients with acute necrotizing pancreatitis. J Gastrointest Surg 2009, I3:768-74.

70. Cinar E, Ateskan U, Baysan A, Mas MR, Comert B, Yasar M, Ozyurt M, Yener N, Mas N, Ozkomur E, Altinatmaz K: Is late antibiotic prophylaxis effective in the prevention of secondary pancreatic infection? Pancreatology 2003, 3:383-8.

7I. Manes G, Uomo I, Menchise A, Rabitti PG, Ferrara EC, Uomo G: Timing of antibiotic prophylaxis in acute pancreatitis: a controlled randomized study with meropenem. Am J Gastroenterol 2006, I0I:1348-53.

72. de Vries AC, Besselink MG, Buskens E, Ridwan BU, Schipper M, van Erpecum KJ, Gooszen HG: Randomized controlled trials of antibiotic prophylaxis in severe acute pancreatitis: relationship between methodological quality and outcome. Pancreatology 2007, 7:531-8.

73. Bai Y, Gao J, Zou DW, Li ZS: Prophylactic antibiotics cannot reduce infected pancreatic necrosis and mortality in acute necrotizing pancreatitis: evidence from a meta-analysis of randomized controlled trials. Am J Gastroenterol 2008, 103:104-10.

Changes Clinical Practice

FI000 Factor 3.2 Recommended

Evaluated by Chris Forsmark 27 Feb 2008, Manoop Bhutani 27 Feb 2008

74. Hart PA, Bechtold ML, Marshall JB, Choudhary A, Puli SR, Roy PK: Prophylactic antibiotics in necrotizing pancreatitis: a metaanalysis. South Med J 2008, I0 I: I |26-3 |

75. Xu T, Cai Q: Prophylactic antibiotic treatment in acute necrotizing pancreatitis: results from a meta-analysis. Scand J Gastroenterol 2008, 43:|249-58.

76. Mazaki T, Ishii Y, Takayama T: Meta-analysis of prophylactic antibiotic use in acute necrotizing pancreatitis. Br J Surg 2006, 93:674-84

77. Besselink MG, van Santvoort HC, Buskens E, Boermeester MA, van Goor H, Timmerman HM, Nieuwenhuijs VB, Bollen TL, van Ramshorst B, Witteman BJ, Rosman C, Ploeg RJ, Brink MA, Schaapherder AF, Dejong CH, Wahab PJ, van Laarhoven C], van der Harst E, van Eijck CH, Cuesta MA, Akkermans LM, Gooszen HG; Dutch Acute Pancreatitis Study Group: Probiotic prophylaxis in predicted severe acute pancreatitis: a randomised, doubleblind, placebo-controlled trial. Lancet 2008, 37 I:65 I-9.

Changes Clinical Practice

FI000 Factor 8.3 Exceptional

Evaluated by Jan De Waele 29 Feb 2008, Ingvar Bjarnason 29 Feb 2008, Bruce Bistrian 3 Mar 2008, Dhiraj Yadav 19 Aug 2008

78. Olah A, Belagyi T, Issekutz A, Gamal ME, Bengmark S: Randomized clinical trial of specific lactobacillus and fibre supplement to early enteral nutrition in patients with acute pancreatitis. $\mathrm{Br} J$ Surg 2002, 89: I 103-7.

79. Olah A, Belagyi T, Poto L, Romics L Jr, Bengmark S: Synbiotic control of inflammation and infection in severe acute pancreatitis: a prospective, randomized, double blind study. Hepatogastroenterology 2007, 54:590-4.

80. Waljee AK, DiMagno MJ, Wu BU, Schoenfeld PS, Conwell DL: Systematic review: pancreatic enzyme treatment of malabsorption associated with chronic pancreatitis. Aliment Pharmacol Ther 2009, 29:235-46. 